\title{
Delivery of paeonol by nanoparticles enhances its in vitro and in vivo antitumor effects
}

This article was published in the following Dove Press journal:

International Journal of Nanomedicine

7 September 2017

Number of times this article has been viewed

\author{
Cong Chen ${ }^{1, *}$ \\ Feng Jia ${ }^{2, *}$ \\ Zhibo Hou ${ }^{3}$ \\ Shu Ruan ${ }^{4}$ \\ Qibin Lu' \\ 'Department of Gynecology of \\ Traditional Chinese Medicine, Jiangsu \\ Province Hospital of Traditional \\ Chinese Medicine, Affiliated Hospital \\ of Nanjing University of Chinese \\ Medicine, Nanjing, ${ }^{2}$ Department of \\ Neurosurgery, Yancheng City No I \\ People's Hospital, The Fourth \\ Affiliated Hospital of Nantong Medical \\ College, Yancheng, ${ }^{3}$ First Department \\ of Respiratory Medicine, Nanjing \\ Chest Hospital, Medical School \\ of Southeast University, Nanjing, \\ ${ }^{4}$ Department of Endocrinology, \\ Yancheng Third Hospital, The Affiliated \\ Hospital of Southeast University \\ Medical College, Yancheng, \\ Jiangsu, China \\ *These authors contributed equally \\ to this work
}

Correspondence: Qibin Lu Department of Gynecology of Traditional Chinese Medicine, Jiangsu Province Hospital of Traditional Chinese Medicine, Affiliated Hospital of Nanjing University of Chinese Medicine, 155 Hanzhong Road, Nanjing, Jiangsu 21 0029, China $\mathrm{Tel} / \mathrm{fax}+862586518612$

Email luqibinwen@I63.com

Shu Ruan

Department of Endocrinology, Yancheng Third Hospital, The Affiliated Hospital of Southeast University Medical College, 75 Juchang Road, Yancheng, Jiangsu 22400I, China

Tel +8651581606102

Fax +8651588303100

Email ycsrshuruan@163.com

\begin{abstract}
Paeonol (Pae; 2'-hydroxy-4'-methoxyacetophenone) has attracted intense attention as a potential therapeutic agent against various cancers. However, the use of Pae is limited owing to its hydrophobicity. Recently, biodegradable polymeric nanoparticles with amphiphilic copolymers have been used as drug carriers; these have better bioavailability and are promising tumor-targeted drug delivery systems. In the current study, we prepared Pae-loaded nanoparticles (Pae-NPs) with amphiphilic block copolymers using nanoprecipitation. The physiochemical characteristics and antitumor effects of nanoparticles were evaluated in different cancer cells. 3-(4,5-Dimethylthiazol-2-yl)-2,5-diphenyltetrazolium bromide assays showed substantial inhibition of cell growth by Pae-NPs. Moreover, lower doses of Pae-NPs inhibited cell growth more efficiently than the equivalent doses of free Pae. Inhibition was characterized by significant elevation of intracellular reactive oxygen species and subsequent inhibition of Akt and regulation of apoptotic proteins, which could be partly reversed by pretreatment with the antioxidant $\mathrm{N}$-acetylcysteine. In vivo results also demonstrated that Pae-NPs could exert much stronger antitumor effects than free Pae. Therefore, Pae-NPs represent a promising delivery system to overcome the low solubility of Pae and enable its use in treating cancer.
\end{abstract}

Keywords: nanoparticles, drug delivery, paeonol

\section{Background}

Lung cancer is the leading cause of cancer-related deaths worldwide. Non-small-cell lung cancer (NSCLC) accounts for about $85 \%$ of cases of lung cancer, while smallcell lung cancer is another major type. Chemotherapy is one of the main treatments used in advanced NSCLC. ${ }^{1}$ However, the effectiveness of chemotherapeutic agents is often hampered by drug resistance and side effects. ${ }^{2}$ There is a necessity to discover novel agents to improve treatment efficacy in patients with advanced NSCLC.

Recently, drug-loaded nanoparticles using amphiphilic copolymers as drug carriers have shown better bioavailability against tumors than free drugs and have potential as tumor-targeted drug delivery systems. ${ }^{3}$ Amphiphilic block copolymer-based polymeric micelles can automatically assemble into nanosized core-shell spherical particles, with the hydrophobic part (eg, poly(caprolactone) [PCL]) as the inner core and the hydrophilic part (eg, poly(ethylene glycol) [PEG]) as the outer shell. Hence, the inner core is amenable to incorporating hydrophobic drugs, which enables a controlled release of the loaded drug due to the strong affinity between the hydrophobic core and the encapsulated drug. Furthermore, the hydrophilic outer shell prevents the nanoparticles from being scavenged effectively by the reticuloendothelial systems, which facilitates their internalization by cells. ${ }^{4}$ 
Paeonol (Pae; 2'-hydroxy-4'-methoxyacetophenone) is a micromolecular phenolic component isolated from the root bark of moutan cortex (Paeonia suffruticosa). There is a growing body of evidence indicating that Pae has antitumor capacity in vitro and in vivo. ${ }^{5-13}$ Pae has been reported to induce apoptosis in various cancer cells, including gastric cancer, esophageal cancer, ovarian cancer, and hepatocellular carcinoma.,6,8,12 One study reported that Pae had a radiosensitizing effect on lung adenocarcinoma cell both in vitro and in vivo. ${ }^{9}$ This radiosensitizing effect is closely related to apoptotic induction, which is caused by the downregulation of the PI3K/Akt signaling pathway. ${ }^{9}$ However, the unsatisfactory bioavailability of Pae, which is due to its poor solubility, greatly limits its applications. ${ }^{14}$ So far, few studies have explored novel formulations of Pae to enhance its bioavailability. Pae-loaded liposomes were successfully constructed by Wu et al, but there was no further antitumor evaluation. $^{15}$

Previous studies have shown that, when used as a sustained drug delivery system, drug-loaded nanoparticles can effectively accumulate in tumor cells by endocytosis, and at the tumor site through the enhanced permeability and retention effect. ${ }^{3,16}$ In this study, methoxy PEG-PCL (mPEG-PCL) nanoparticles were adopted as drug carriers to prepare Pae-loaded nanoparticles (Pae-NPs). First, the size, zeta potential, loading efficiency, and in vitro release pattern of Pae-NPs were characterized by physiochemical methods, and the cytotoxic discrepancy between free Pae and Pae-NPs was measured by 3-(4,5-dimethylthiazol-2-yl)2,5-diphenyltetrazolium bromide (MTT) assays. Next, we measured changes in apoptosis and oxidative stress in A549 NSCLC cancer cells in response to treatment with free Pae and Pae-NPs, to elucidate the differential antitumor effects of Pae and Pae-NPs. Finally, we examined the in vivo antitumor effects of Pae-NPs in a NSCLC xenograft cancer model using A549 cells. We hypothesize that Pae-NPs activate pro-apoptotic, and suppress anti-apoptotic, signal molecules simultaneously in cancer cells, through inducing intracellular reactive oxygen species (ROS) generation and inhibiting the phosphorylation of Akt.

\section{Materials and methods Materials}

Pae was purchased from Nanjing Haoxuan Biotechnological Co Ltd (Nanjing, China). Human NSCLC cell lines A549 and NCI-H1975 were obtained from the Shanghai Institute of Cell Biology (Shanghai, China). Cell culture material (RPMI 1640 media and fetal bovine serum) was from
Thermo Fisher Scientific (Waltham, MA, USA). The cells were cultured in RPMI 1640 medium supplemented with $10 \%$ fetal bovine serum, $100 \mathrm{U} / \mathrm{mL}$ penicillin, and $100 \mathrm{U} / \mathrm{mL}$ streptomycin at $37^{\circ} \mathrm{C}$ in a $5 \% \mathrm{CO}_{2}$ humidified atmosphere. MTT and N-acetylcysteine (NAC) were purchased from Sigma-Aldrich (St Louis, MO, USA). Antibodies against phosphate-Akt, Akt, Bcl-XL, Bax, Bcl-2, caspase-3, cleaved caspase-3, and $\beta$-actin were obtained from Cell Signaling Technology, Inc (Danvers, MA, USA). All other chemicals were of analytical grade.

\section{Methods}

\section{Formulation of nanoparticles}

Pae-NPs were constructed by a nanoprecipitation method as described previously, ${ }^{16,17}$ with minor modifications. ${ }^{16,17}$ Forty milligrams of mPEG10k-PCL30k block copolymers and $8 \mathrm{mg}$ Pae were dissolved in $3 \mathrm{~mL}$ acetone, which was then added dropwise into $30 \mathrm{~mL}$ double-distilled water with slight-to-moderate stirring at room temperature. The solution was then transferred into a dialysis bag (molecular weight [MW] $12 \mathrm{kD}$ ) and rinsed in double-distilled water for 2 hours, changing the medium every 10 minutes to remove all acetone. The solution was then filtered through a $0.22 \mu \mathrm{m}$ membrane to remove free drugs and copolymer aggregates. Coumarin-6 (a green hydrophobic fluorescent marker) and Pae co-loaded nanoparticles were prepared by simultaneous encapsulation of Pae and coumarin-6. Blank nanoparticles were prepared without addition of drugs. Solutions of nanoparticles were then freeze-dried with F-68 as a cryoprotectant before use.

\section{Characterization of nanoparticles and stability test}

Dynamic light scattering (DLS) was applied to detect the mean diameter and distribution of Pae-NPs (Brookhaven BI-9000AT instrument; Brookhaven Instruments Corporation, NY, USA), while laser Doppler anemometry was adopted to measure the zeta potential of the particles (ZetaPlus Zeta Potential Analyzer; Brookhaven Instruments Corporation). The solution of Pae-NPs was kept at room temperature. The size of the nanoparticle was measured by DLS every 2 days for 11 days.

\section{Drug loading content (DLC) and encapsulation efficiency (EE)}

High-performance liquid chromatography (HPLC) was used to analyze the loading efficiency of Pae-NPs (Shimadzu LC-10AD; Shimadzu, Japan). The mobile phase consisted of methanol (spectral grade; EMD Millipore, Billerica, MA, USA) and double-distilled water $(60 / 40, \mathrm{v} / \mathrm{v})$ pumped at 
a flow rate of $0.8 \mathrm{~mL} / \mathrm{min}$, with a determination wavelength of $274 \mathrm{~nm} .{ }^{18}$ Equations 1 and 2 were applied to calculate the DLC and EE, respectively.

$$
\begin{aligned}
& \operatorname{DLC}(\%)=\frac{\text { Weight of the drug in nanoparticles }}{\text { Weight of the nanoparticles }} \times 100 \\
& \operatorname{EE}(\%)=\frac{\text { Weight of the drug in nanoparticles }}{\text { Weight of the feeding drugs }} \times 100
\end{aligned}
$$

\section{In vitro release of Pae-NPs}

In vitro release was detected by dialysis as reported previously. ${ }^{16,17}$ Briefly, $10 \mathrm{mg}$ Pae-NPs powder was dissolved in $1 \mathrm{~mL}$ of $0.1 \mathrm{M}$ phosphate-buffered saline (PBS; $\mathrm{pH}$ 7.4) and then transferred into a dialysis bag, followed by immersion in $20 \mathrm{~mL}$ PBS at room temperature. At each time point, $1 \mathrm{~mL}$ liquid was taken from the medium outside the dialysis bag and the Pae concentration was measured using HPLC as described above.

\section{Nanoparticle uptake by cancer cells}

To assess the uptake efficiency of Pae-NPs, we applied coumarin-6 as a tracer of nanoparticles incubated with cancer cells. ${ }^{16,17}$ A549 or NCI-H1975 cells $\left(5 \times 10^{5}\right)$ were seeded in 6-well plates with RPMI 1640 supplemented with 10\% fetal bovine serum and allowed to adhere at $37^{\circ} \mathrm{C}$ with $5 \% \mathrm{CO}_{2}$ for 24 hours. Next, the cells were incubated with coumarin- 6 and Pae co-loaded nanoparticles for 2 hours with or without co-treatment with $10 \mathrm{mM} \mathrm{NaN}_{3}$, an endocytosis inhibitor. The cells were washed three times with PBS and then observed under a fluorescent microscope (LSM 410; Carl Zeiss Meditec AG, Jena, Germany). For the assessment of the uptake efficiency of Pae, free Pae was incubated with cancer cells at the same concentration and subjected to HPLC detection.

To quantify the uptake efficiency of Pae and Pae-NPs, we used HPLC to measure the intracellular drug concentration. Cancer cells were incubated with Pae-NPs for 2 hours and then washed out with PBS three times. The suspension was centrifuged at $1,500 \times g$. The pellet was reconstituted in the mobile phase, sonicated for 30 seconds, and subjected to HPLC detection. ${ }^{18}$

\section{In vitro cytotoxicity studies}

The in vitro antitumor effect of Pae-NPs against A549 and NCI-H1975 cells was evaluated by MTT assay, as reported in our previous study. ${ }^{16}$ Briefly, both cells were seeded in 96-well plates with a density of around 5,000 cells/well and allowed to adhere for 24 hours prior to the assay. Cells were exposed to a series of equivalent doses of free Pae or Pae-NPs $(20,40,80,160,320$, and $640 \mu \mathrm{g} / \mathrm{mL})$ at $37^{\circ} \mathrm{C}$ for 48 hours. The cells were then washed with PBS three times, and $50 \mu \mathrm{L}$ MTT indicator dye ( $5 \mathrm{mg} / \mathrm{mL}$ in PBS, $\mathrm{pH} 7.4)$ was added to each well and incubated for 2 hours at $37^{\circ} \mathrm{C}$ in the dark. The cultured medium was replaced by $200 \mu \mathrm{L}$ acidified isopropanol $(0.33 \mathrm{~mL} \mathrm{HCl}$ in $100 \mathrm{~mL}$ isopropanol) to dissolve the formazan crystals. The absorption was detected at a wavelength of $550 \mathrm{~nm}$ by a microkinetics reader.

\section{Detection of intracellular ROS levels}

Intracellular ROS levels were measured with dihydroethidium (DHE) as described previously. ${ }^{16}$ Briefly, A549 cells at a density of $2 \times 10^{5}$ were co-incubated with Pae or Pae-NPs at an equivalent dose of $50 \mu \mathrm{g} / \mathrm{mL}$ for 48 hours, with or without the co-treatment of NAC at a concentration of $1 \mathrm{mM}$. Next, $10 \mu \mathrm{M}$ DHE was incubated with cells for 30 minutes and then washed by PBS. The red fluorescence of DHE was immediately observed by a fluorescent microscope and simultaneously measured by a fluorescent spectrophotometer with an emission wavelength at $610 \mathrm{~nm}$ and an excitation wavelength of $535 \mathrm{~nm}$.

\section{Apoptosis analysis}

For apoptosis analysis, A549 cells were treated with $50 \mu \mathrm{g} / \mathrm{mL}$ free Pae or Pae-NPs for 48 hours in the presence or absence of $1 \mathrm{mM}$ NAC pretreated for 2 hours. Quantification of apoptotic cells was performed with annexin-V-fluorescein isothiocyanate (FITC) and propidium iodide (PI) Apoptosis Detection Kit (Thermo Fisher Scientific) according to the manufacturer's instructions. Cells were then washed and transferred into $1 \times$ annexin- $V$ binding buffer at a concentration of $1 \times 10^{6}$ cells $/ \mathrm{mL}$. An aliquot of $100 \mu \mathrm{L}$ of suspension $\left(1 \times 10^{5}\right.$ cells) was stained with $5 \mu \mathrm{L}$ annexin-V-FITC and $5 \mu \mathrm{L}$ $\mathrm{PI}$, and then incubated for 15 minutes at room temperature in the dark. Cell analyses were then performed using a FACScan flow cytometer (BD Biosciences, San Jose, CA, USA).

\section{Western blot analysis}

For protein extraction, A549 cells were treated with $50 \mu \mathrm{g} / \mathrm{mL}$ free Pae or Pae-NPs for 48 hours in the presence or absence of $1 \mathrm{mM}$ NAC pretreated for 2 hours. Confluent cells were denatured in lysis buffer (containing $20 \mathrm{mM}$ Tris- $\mathrm{HCl}$, $200 \mathrm{mM} \mathrm{NaCl}, 0.2 \% \mathrm{NP}-40,0.5 \%$ Triton X-100, and protease inhibitors) and boiled at $95^{\circ} \mathrm{C}$ for 3 minutes. Equal amounts of protein extract were separated on $12 \%$ polyacrylamide gels using standard sodium dodecyl sulfate polyacrylamide gel electrophoresis, and then transferred onto polyvinylidene 
difluoride membranes (Bio-Rad Laboratories Inc, Hercules, CA, USA). Following blocking in Tris-buffered saline with $0.1 \%$ Triton $\mathrm{X}-100$ and $5 \%$ milk, the membranes were incubated at $4^{\circ} \mathrm{C}$ overnight with different primary antibodies against phosphate-Akt (dilution, 1:1,000; no 4060), Akt (dilution, 1:1,000; no 4685), Bcl-XL (dilution, 1:1,000; no 2762), Bax (dilution, 1:1,000; no 5023), Bcl-2 (dilution, 1:1,000; no 2870), caspase-3 (dilution, 1:1,000; no 9665), cleaved caspase-3 (dilution, 1:1,000; no 9664), and $\beta$-actin (dilution, 1:1,000; no 4970), respectively. Following washing, the membranes were incubated with secondary antibody (dilution, 1:3,000; no 7074) conjugated to horseradish peroxidase at room temperature for 2 hours. Signal detection was carried out on an imager (Syngene, Frederick, MD, USA) using an enhanced chemiluminescence system (Thermo Fisher Scientific).

In vivo evaluation of Pae-NPs in a xenograft model Five-week-old BALB/C-nu/nu nude mice were obtained from the Shanghai Laboratory Animal Center of China. The Animal Care Committee of Nanjing University of Chinese Medicine approved this study. Housing and all of the animal experiments were conducted according to the protocol approved by the Animal Care Committee of Nanjing University of Chinese Medicine. A549 cells (1-1.5×106) were harvested, washed, and resuspended in $200 \mu \mathrm{L}$ serum-free medium, and were subcutaneously implanted into the right flanks of nude mice. Tumor volumes $\left(\mathrm{mm}^{3}\right)$ were defined using the following formula: $\mathrm{V}=\left(\right.$ length $\times$ width $\left.^{2}\right) / 2 .{ }^{19}$ When the tumors reached a mean volume of $100 \mathrm{~mm}^{3}$, the mice were randomly divided into four groups $(n=8)$. Each group of mice was then treated with vehicle (PBS), empty NPs (E-NPs), free Pae, or Pae-NPs, respectively, administered through the tail vein in a volume of $200 \mu \mathrm{L}$ as shown in Table 1. Free Pae solution was administered at doses of $40 \mathrm{mg} / \mathrm{kg}$. Pae-NPs were administered as a saline solution at equivalent doses of $40 \mathrm{mg} / \mathrm{kg}$. The day that mice were treated with drugs was designated day 1 . Tumor volumes were then monitored every other day with calipers during the treatment. To evaluate possible toxic effects of the therapy, the body

Table I Parameters of the in vivo study

\begin{tabular}{lll}
\hline Group & Dose & Route \\
\hline Control & - & Tail vein \\
E-NPs & - & Tail vein \\
Pae & $40 \mathrm{mg} / \mathrm{kg}$ & Tail vein \\
Pae-NPs & $40 \mathrm{mg} / \mathrm{kg}$ & Tail vein \\
\hline
\end{tabular}

Abbreviations: Pae, paeonol; Pae-NPs, Pae-loaded nanoparticles; E-NPs, empty nanoparticles. weight of each mouse was also measured during the period of study. At the end of the experiment, survival curves were calculated by Kaplan-Meier analysis.

\section{Statistical analysis}

Values are presented as mean \pm SD from triplicate experiments. The results were analyzed by analysis of variance or Student's $t$-test with SPSS 11.5 (SPSS Inc, Chicago, IL, USA). A difference of $p<0.05$ was considered statistically significant.

\section{Results and discussion Characterization of nanoparticles}

The diameters of Pae-NPs are around $60 \mathrm{~nm}$, with a negative zeta potential slightly below $0 \mathrm{mV}$ (Figure 1A; Table 2). In a previous study, a PEG coating was shown to greatly neutralize the negative zeta potential of nanoparticles. ${ }^{20,21}$ The satisfactory loading efficiency was attributed to the affinity between lipophilic Pae and the inner PCL core. ${ }^{22,23}$ By varying the feeding ratio of the copolymer and Pae, the highest DLC for Pae in mPEG10k-PCL30k nanoparticles was $16.3 \% \pm 2.4 \%$, and $\mathrm{EE}$ was $>94.3 \% \pm 4.4 \%$ (Table 1 ). In addition, Figure 1B shows that the size of Pae-NPs slightly increased over time at room temperature, which indicates that Pae-NPs had good stability in vitro. Figure $1 \mathrm{C}$ shows the sustained release pattern of Pae-NPs. After the initial burst of about $30 \%$ release in the first few hours, the release speed gradually decreased, with nearly $70 \%$ of Pae being released from the nanoparticles. This indicates that Pae can be released from $\mathrm{MPEG}-\mathrm{PCL}$ nanoparticles in a controlled manner, meaning that Pae-NPs could be used as a potential controlled release system for cancer therapy.

\section{In vitro cytotoxicity of Pae-NPs against cancer cells}

Figure 2 shows the in vitro cytotoxicity of Pae-NPs. E-NPs were almost nontoxic to A549 cells, even at a concentration of $5 \mathrm{mg} / \mathrm{mL}$ (Figure 2A). Both Pae and Pae-NPs dosedependently inhibited the proliferation of A549 cells when incubated with A549 cells for 48 hours; however, Pae-NPs induced more cell death than did the equivalent dose of Pae. Most importantly, lower concentrations of Pae-NPs (20, 40, and $80 \mu \mathrm{g} / \mathrm{mL}$ ) significantly inhibited cell growth compared with the equivalent dose of Pae. Specifically, $20 \mu \mathrm{g} / \mathrm{mL}$ PaeNPs resulted in nearly $30 \%$ cell death, compared with $<15 \%$ for treatment with the same dose of Pae $(p<0.05)$. It is also notable that more significant cell growth inhibition was observed in cells exposed to 40 or $80 \mu \mathrm{g} / \mathrm{mL}$ Pae-NPs 

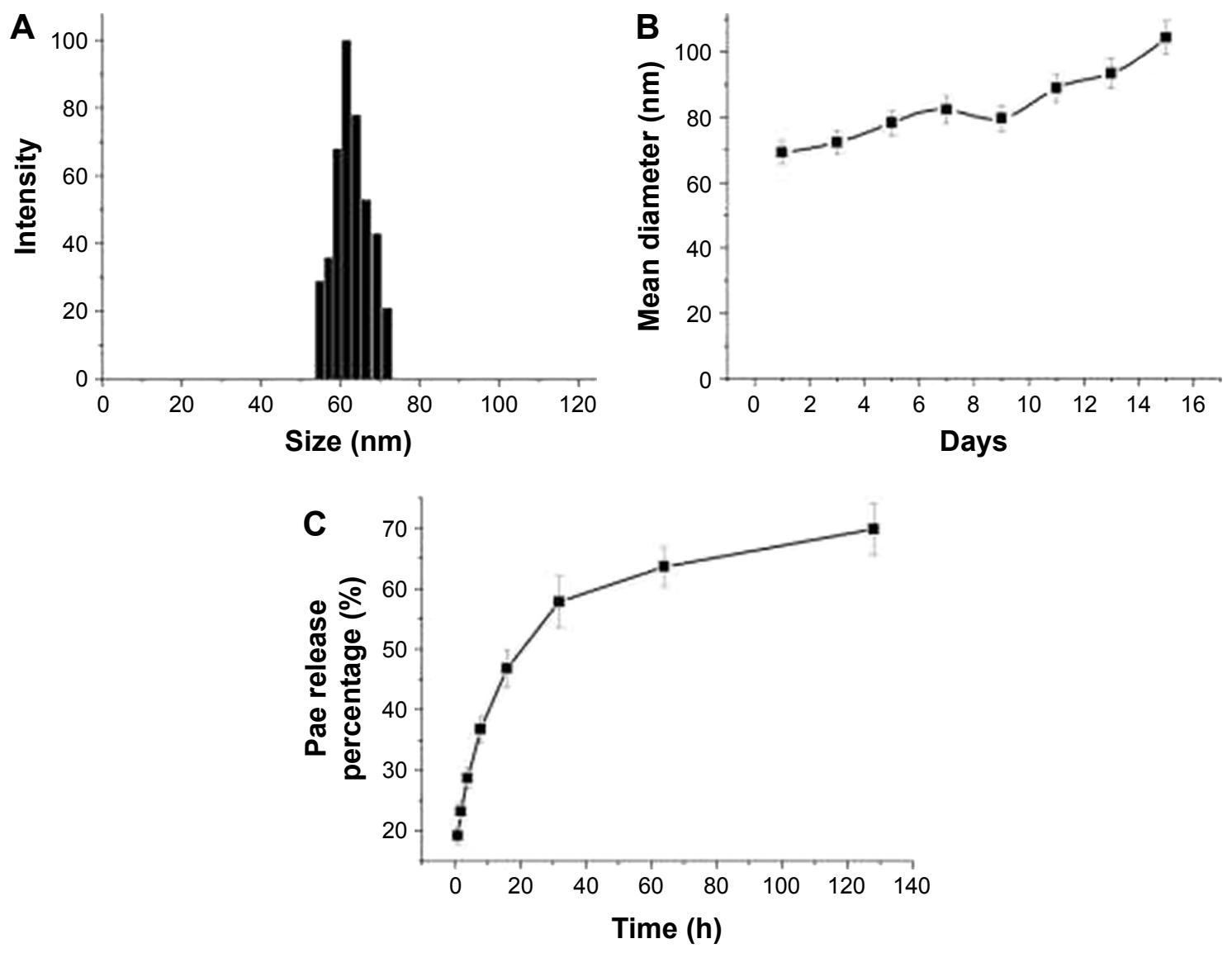

Figure I Characterization of Pae-NPs.

Notes: (A) Size distribution of Pae-NPs measured by DLS. (B) Size changes of Pae-NPs at room temperature. (C) Cumulative release profile of Pae-NPs. Abbreviations: Pae-NPs, Pae-loaded nanoparticles; DLS, dynamic light scattering.

compared with the equivalent doses of Pae $(p<0.01)$. The same trend was observed in the cytotoxicity curve for NCIH1975 cells (Figure 2B). Pae-NPs showed a dose-dependent cytotoxicity, which was stronger than that observed for the equivalent dose of free Pae.

It has been demonstrated in earlier studies that drugloaded nanoparticles exhibit stronger cytotoxicity than the free drug owing to endocytosis-based cellular uptake, ${ }^{24}$ which is supported by the current findings. As a significant difference is observed in cells exposed to lower doses of Pae and Pae-NPs, a dose of $50 \mu \mathrm{g} / \mathrm{mL}$ was applied in further experiments to study the discrepancy between Pae-NPs and

Table 2 Mean particle size and drug loading efficiency of Pae-NPs

\begin{tabular}{lllll}
\hline $\begin{array}{l}\text { Feeding } \\
\text { ratio }\end{array}$ & $\begin{array}{l}\text { Particle } \\
\text { size }(\mathbf{n m})^{\mathrm{a}}\end{array}$ & $\begin{array}{l}\text { Zeta } \\
\text { potential (Mv) }\end{array}$ & DLC (\%) & EE (\%) \\
\hline $15 \%$ & $63.5 \pm 7.3$ & $-3.7 \pm 0.8$ & $13.6 \pm 1.4$ & $92.6 \pm 3.1$ \\
\hline
\end{tabular}

Note: ${ }^{\mathrm{a} T}$ The SD value was for the mean particle size obtained from three measurements of a single batch.

Abbreviations: DLC, drug loading content; EE, encapsulation efficiency; Pae-NPs, Pae-loaded nanoparticles; SD, standard deviation. free Pae by detection of apoptosis and relative apoptotic protein expression.

\section{Uptake of nanoparticles by cancer cells}

The cellular uptake of coumarin-6-loaded Pae-NPs by A549 cells was measured by fluorescence microscopy. The fluorescence, which indicates the location of the nanoparticles, was observed mainly in the cytoplasm rather than the nucleus (Figure 3A and B). A 2-hour incubation allowed the A549 cells to take up nanoparticles efficiently, with $>20 \%$ of Pae located intracellularly. The same fluorescence was observed in NCI-H1975 cells when incubated with coumarin6-loaded Pae-NPs. Quantification studies showed that the uptake efficiency of Pae-NPs by NCI-H1975 cells was $<20 \%$ (Figure 3C). Moreover, the uptake efficiency could be significantly decreased by $\mathrm{NaN}_{3}$, an endocytosis inhibitor, which demonstrated that the uptake process was significantly dependent on endocytosis (Figure 3C). In addition, the uptake efficiency of Pae-NPs by cancer cells was much higher than that of free Pae (Figure S1), which demonstrates 

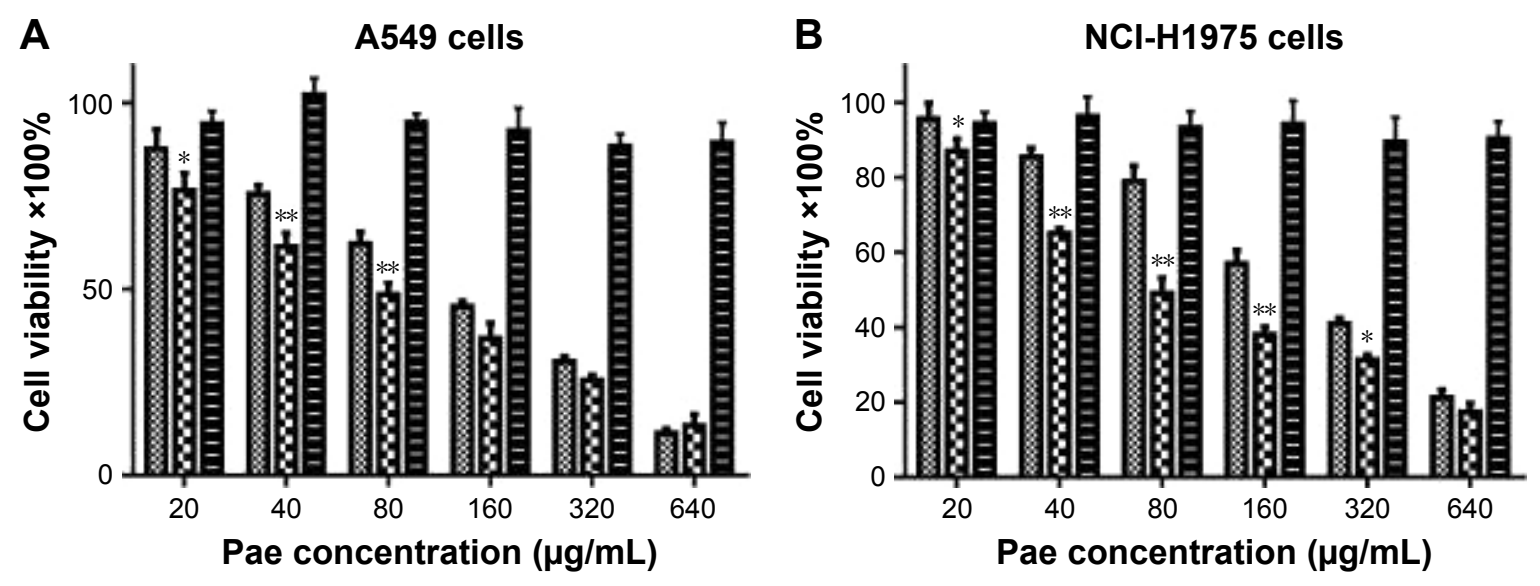

$\approx$ Pae $\quad \longrightarrow$ Pae-NPs $\longrightarrow$ E-NPs

Figure 2 Dose-dependent cytotoxicity of Pae and Pae-NPs against (A) A549 and (B) NCl-HI 975 cells.

Notes: Data are presented as mean \pm SD $(n=3)$. $*_{p}<0.05$, ${ }^{*} p<0.01$, compared to the control group.

Abbreviations: Pae, paeonol; Pae-NPs, Pae-loaded nanoparticles; E-NPs, empty nanoparticles; SD, standard deviation.

the efficient penetration of nanoparticles through endocytosis. Previous studies have also reported that the uptake of nanoparticles by cells occurs mainly through endocytosis. However, if it exceeds the saturable capacity of cellular endocytosis, the uptake efficiency will no longer increase as the concentration elevates. ${ }^{25}$ Here, A549 cells were used because of the relatively higher uptake efficiency and stronger cytotoxicity of Pae-NPs.
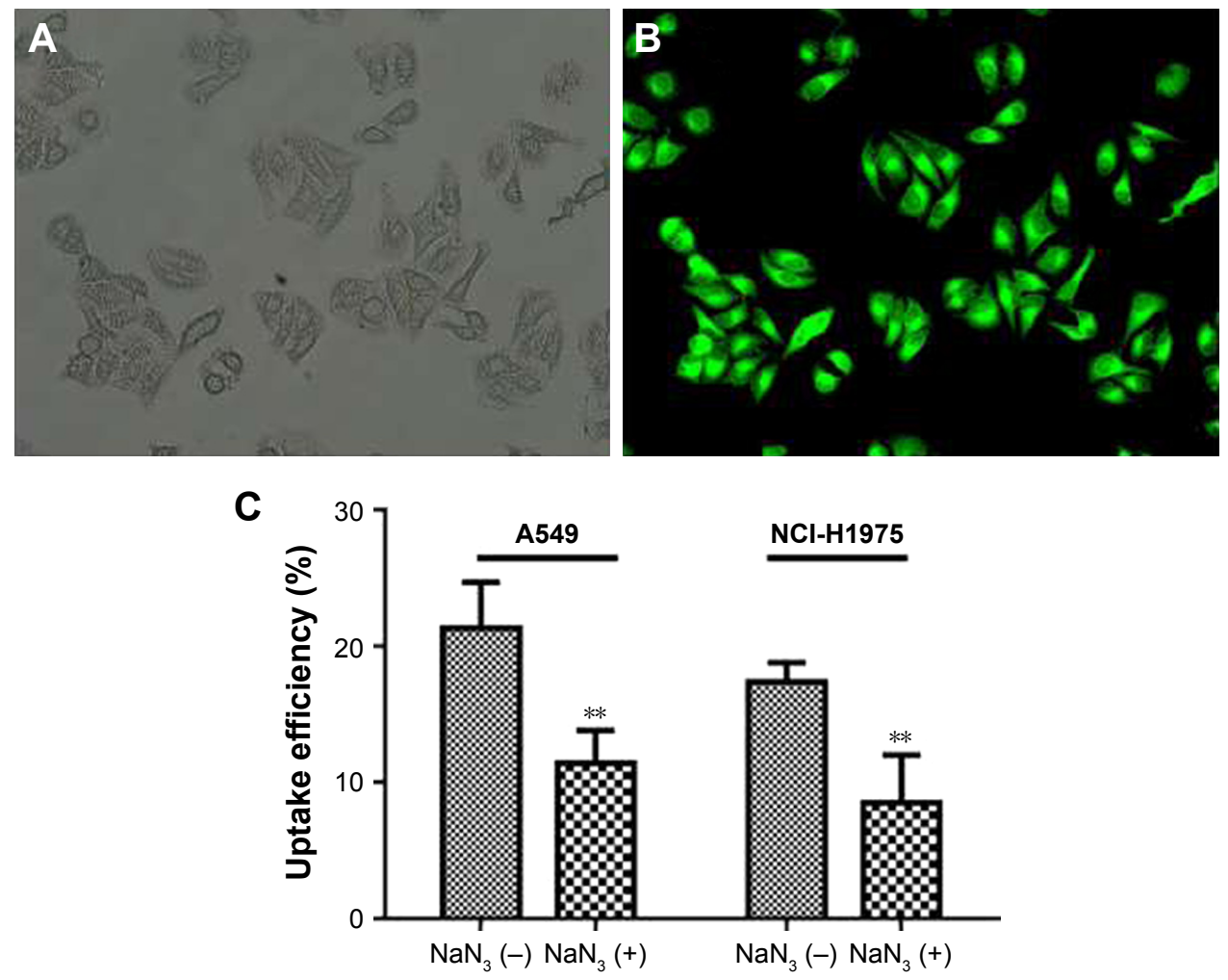

Figure 3 Cellular uptake of coumarin-6-loaded fluorescent Pae-NPs by cancer cells.

Notes: (A, B) Representative microscopic images of A549 cells incubated with coumarin-6-loaded Pae-NPs for 2 hours; (A) bright fields with higher magnification; (B) fluorescent fields with higher magnification. (C) Cellular uptake efficiency of Pae-NPs by A549 and NCl-HI 975 cells. Data are presented as mean \pm SD ( $=3$ ). ** $p<0.0$ I, compared to the control group.

Abbreviations: Pae-NPs, Pae-loaded nanoparticles; SD, standard deviation. 


\section{Apoptotic induction of Pae-NPs}

Several studies have reported that Pae could promote apoptosis in several tumor cells. ${ }^{5,6,8,12}$ To examine the apoptotic effect of E-NPs, free Pae, and Pae-NPs, cells were treated with a dose of $50 \mu \mathrm{g} / \mathrm{mL}$ of these agents for 48 hours. Apoptosis was detected using flow cytometry assays with an annexin-V-FITC/PI kit. Both the free Pae and Pae-NPs promoted apoptosis in A549 cells compared with E-NPs (Figure 4A). It is notable that the proportion of early apoptotic cells induced by Pae-NPs was significantly higher than that induced by free Pae (23.36\% vs $15.86 \%$ ). These results indicate that Pae-NPs elicited significantly more apoptosis at almost equivalent dose and incubation time.

\section{Detection of ROS level induced by Pae-NPs}

It is known that the balance between ROS and antioxidant capacity is a major determinant of cell destiny, as elevation of ROS can induce apoptosis. ${ }^{26}$ In addition, many studies have shown that some chemotherapeutic agents can induce apoptosis in certain types of cancer cells through overproduction of intracellular ROS..$^{13,27-29}$ Therefore, we investigated whether Pae treatment could increase ROS levels in A549 cells. We found that both free Pae and Pae-NPs increased ROS generation, and Pae-NPs induced more accumulation of ROS. There was no significant difference in intracellular ROS levels between cells treated with control and with E-NPs
(Figure 5A). However, cells treated with free Pae or Pae-NPs showed increased intracellular ROS levels of 1.80- or 2.29fold of control values, respectively ( $p=0.01$, Pae vs control; $p=0.01$, Pae-NPs vs control) (Figure 5B). These data show the increase in intracellular ROS levels with Pae treatment while Pae-NPs induced more intracellular ROS.

Next, to further investigate whether ROS plays an important part in Pae-induced apoptosis, NAC was used to block accumulation of ROS in A549 cells. ROS accumulation was blocked more obviously by NAC in Pae-treated cells (up to $27.2 \%$ ) in contrast to Pae-NP-treated cells (up to $13.5 \%$ ) (Figure 5). Simultaneously, with NAC pretreatment, the apoptosis induced by free Pae was attenuated more significantly than that induced by Pae-NPs $(18.29 \%$ vs $8.97 \%$ ), which is consistent with ROS attenuation being blocked by NAC (Figure 4B). These data suggest that the proapoptotic effect of free Pae and Pae-NPs is partly dependent on the generation of ROS.

\section{Modulation of AKT/apoptotic pathways by Pae-NPs}

The regulation of Akt in apoptosis through its downstream pathways remains to be implicated in cancer. ${ }^{30-32}$ It is known that suppression of Akt activation is an important mechanism in ROS-induced apoptosis in tumor cells. ${ }^{26}$ To determine the role of Akt in Pae-NP-induced lung cancer cell apoptosis, Western blot analysis was used to evaluate Akt-related
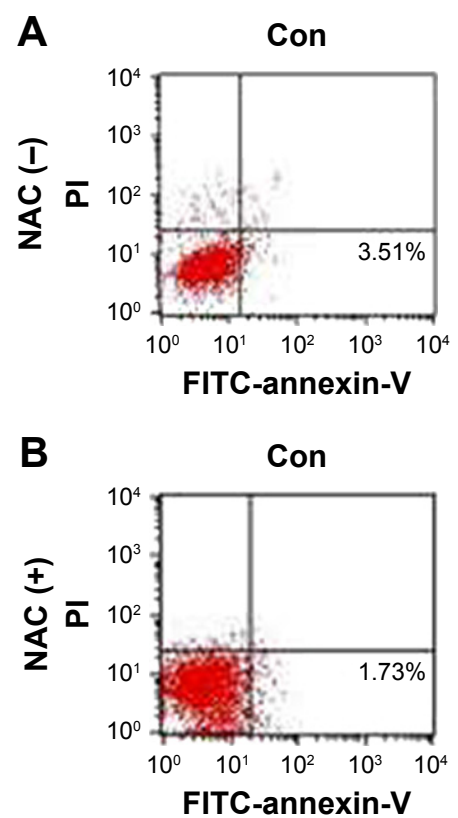

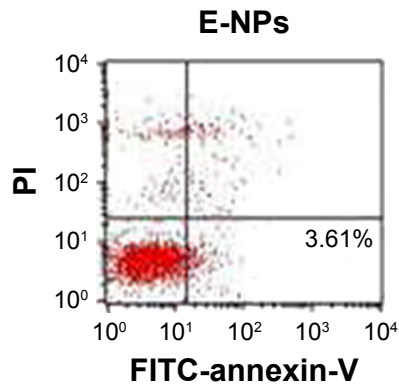

E-NPs

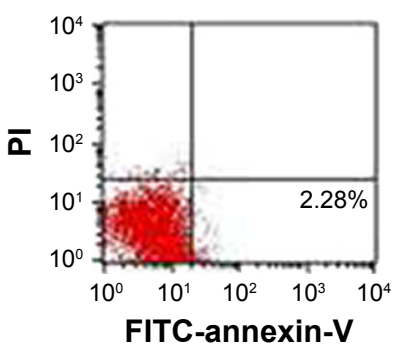

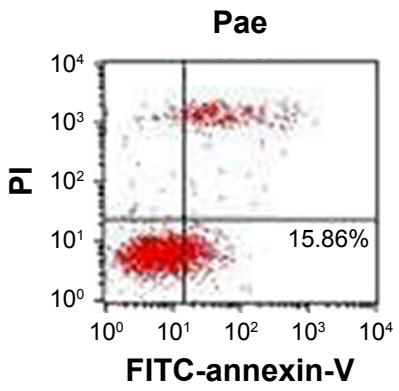
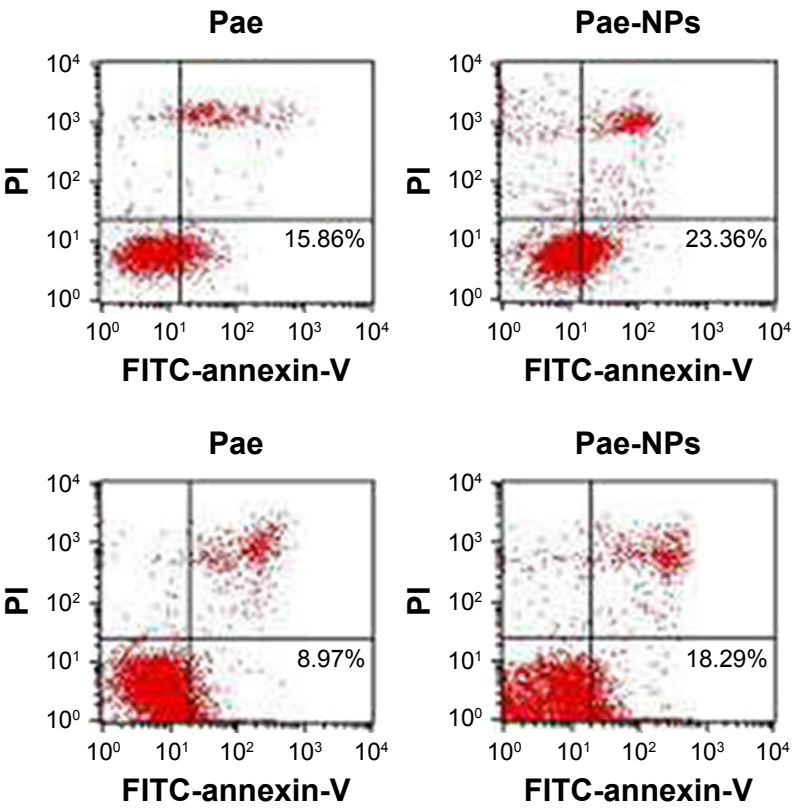

Figure 4 Effects of Pae and Pae-NPs on apoptosis in A549 cells without (A) or with (B) the presence of NAC.

Abbreviations: Pae, paeonol; Pae-NPs, Pae-loaded nanoparticles; E-NPs, empty nanoparticles; NAC, N-acetylcysteine; Con, control; FITC, fluorescein isothiocyanate; $\mathrm{Pl}$, propidium iodide. 

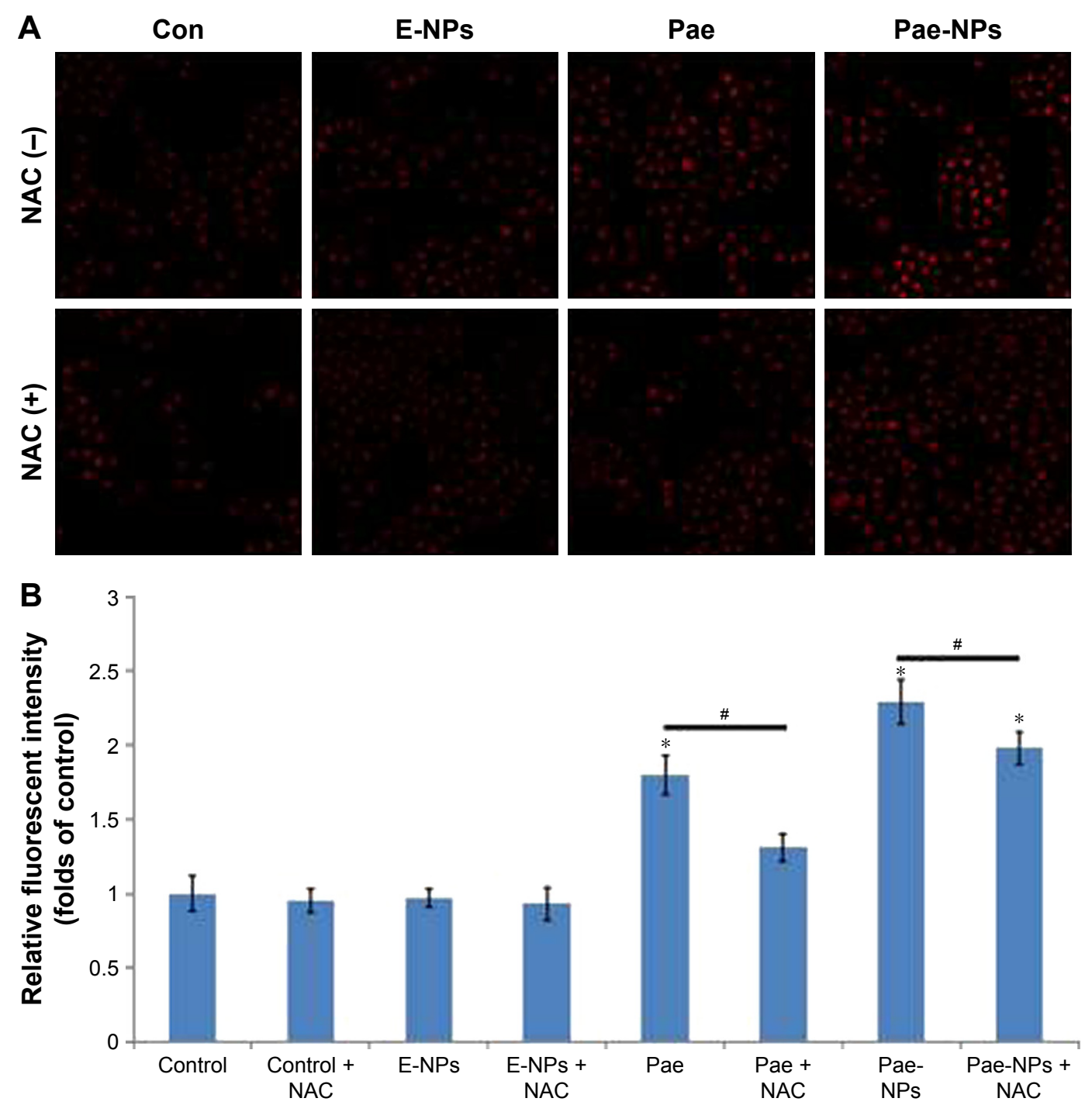

Figure 5 Detection of intracellular ROS.

Notes: (A) DHE fluorescence images of A549 cells treated with different agents (control; E-NPs; Pae [50 $\mu g / \mathrm{mL}]$; Pae-NPs [at an equivalent dose of $50 \mu \mathrm{g} / \mathrm{mL}$ ]). (B) Intracellular DHE fluorescence intensity. Data are represented as mean \pm SD. ${ }^{*} p<0.05$, compared to the control group; ${ }^{*} p<0.05$, compared to the Pae group or Pae-NPs group. Abbreviations: Pae, paeonol; Pae-NPs, Pae-loaded nanoparticles; E-NPs, empty nanoparticles; SD, standard deviation; DHE, dihydroethidium; ROS, reactive oxygen species; NAC, N-acetylcysteine; Con, control.

proteins after Pae-NPs treatment. A549 cells were treated with a dose of $50 \mu \mathrm{g} / \mathrm{mL}$ of either free Pae or Pae-NPs. The results showed that phosphorylated Akt levels decreased more significantly after Pae-NPs treatment than after free Pae treatment (Figure 6).

Our data further indicated that protein expression of Bcl-2 and Bcl-XL was significantly decreased, whereas the expression of Bax proteins was increased, in A549 cells treated with free Pae or Pae-NPs (Figure 7). In accordance with the apoptosis results, the expression of the anti-apoptotic proteins Bcl-2 and Bcl-XL was decreased more significantly in Pae-NP-treated A549 cells than in free Pae-treated cells. Similarly, the expression of the pro-apoptotic protein Bax was increased more significantly in Pae-NP-treated
A549 cells. These results indicate that Pae-NPs exert a greater pro-apoptotic effect than free Pae.

During the initiation and progression of apoptosis, caspase- 3 has a key role, and its activation is a characteristic of apoptosis. ${ }^{33,34}$ The expression of caspase- 3 was examined to determine whether Pae led to caspase-dependent apoptosis. The cleavage of caspase- 3 was markedly elevated in A549 cells treated with Pae-NPs compared with free Pae (Figure 8).

Following removal of the ROS by NAC, we next studied the expression levels of phosphorylated Akt, Bcl-2, Bcl-XL, and Bax, and cleavage of caspase- 3 in A549 cells treated with free Pae or Pae-NPs. We found that the increased levels of phosphorylated Akt and caspase- 3 cleavage by Pae or Pae-NPs were rescued with NAC pretreatment, especially 
A

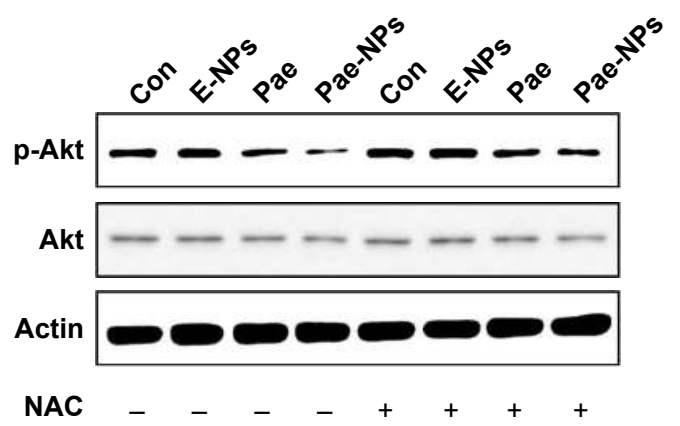

B

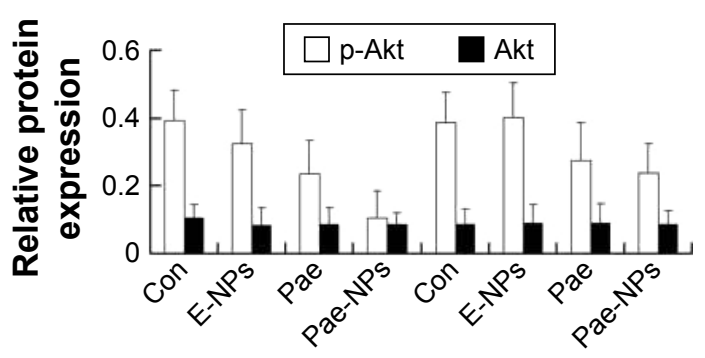

Figure 6 Effects of free Pae or Pae-NPs on the expression of Akt pathway proteins in $\mathrm{A} 549$ cells.

Notes: (A) Blots of $p$-Akt and Akt from cells treated with different agents. (B) Semiquantification of protein expression. Data are represented as mean \pm SD. Abbreviations: Pae, paeonol; Pae-NPs, Pae-loaded nanoparticles; E-NPs, empty nanoparticles; SD, standard deviation; NAC, N-acetylcysteine; Con, control.

A

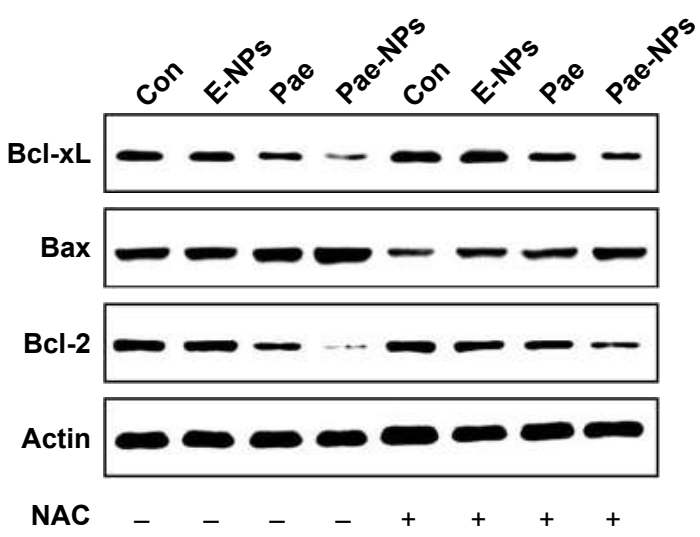

B

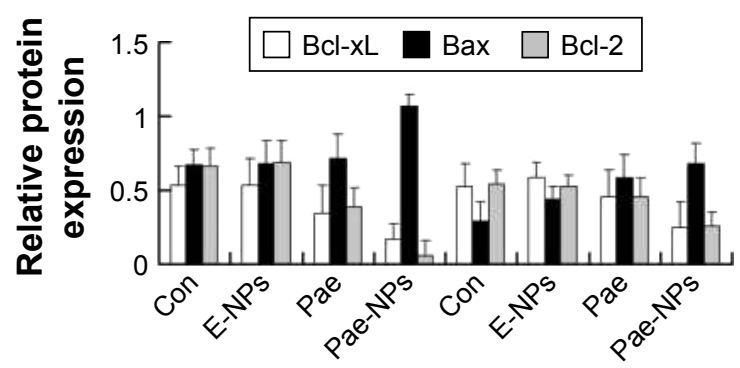

Figure 7 Effect of free Pae or Pae-NPs on the expression of apoptotic proteins in A549 cells.

Notes: (A) Blots of $\mathrm{Bcl}-\mathrm{XL}, \mathrm{Bax}$, and $\mathrm{Bcl}-2$ from cells treated with different agents. (B) Semi-quantification of protein expression. Data are represented as mean $\pm \mathrm{SD}$. Abbreviations: Pae, paeonol; Pae-NPs, Pae-loaded nanoparticles; E-NPs, empty nanoparticles; SD, standard deviation; NAC, N-acetylcysteine; Con, control.
A

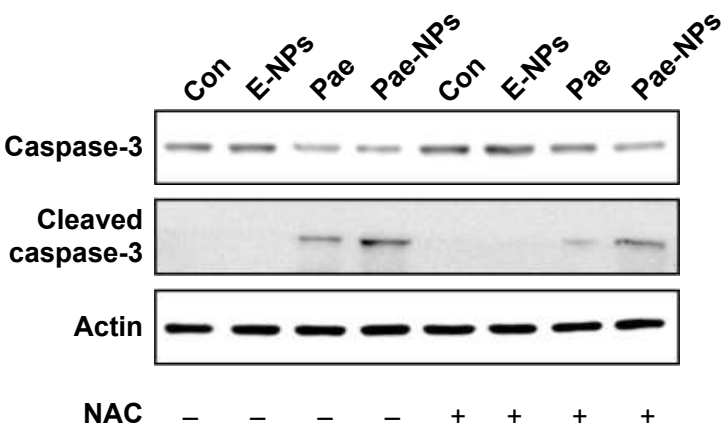

B

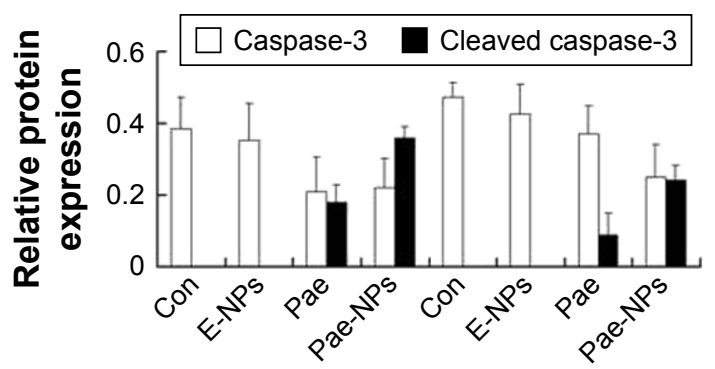

Figure 8 Effect of free Pae or Pae-NPs on the expression of caspase-3 and cleaved caspase-3 proteins in A549 cells.

Notes: (A) Blots of caspase-3 and pro-caspase-3 from cells treated with different agents. (B) Semi-quantification of protein expression. Data are represented as mean \pm SD.

Abbreviations: Pae, paeonol; Pae-NPs, Pae-loaded nanoparticles; E-NPs, empty nanoparticles; SD, standard deviation; NAC, N-acetylcysteine; Con, control.

in the case of free Pae treatment (Figures 6 and 8). NAC pretreatment could partially prevent free Pae or Pae-NPs from inducing the expression of Bax and reversing the decrease of Bcl-2 and Bcl-XL (Figure 7). Most importantly, NAC inhibited the expression of Bax and recovered the expression of Bcl-2 and Bcl-XL induced by free Pae much more significantly. Therefore, these results show that Pae-induced apoptosis results from the initial generation of ROS and the following inhibition of the Akt pathway, which appears to be the downstream event of ROS elevation. Pae-NPs statistically surpassed free Pae in apoptotic induction through regulating the ROS-dependent Akt pathway and the downstream caspase cascade.

Although it has been shown that Pae-induced apoptosis is characterized by the activation of caspase- 3 and inhibition of surviving, ${ }^{6}$ decrease in the Bcl-2/Bax ratio, ${ }^{5,8,12}$ and stimulation of interleukin (IL)-2 and tumor necrosis factor (TNF)- $\alpha$ production, ${ }^{12}$ the exact mechanism remains unclear. Previous studies have demonstrated that the mechanism of Pae's antitumor effect is via induction of apoptosis, stimulation of IL-2, and TNF- $\alpha$ production. . $^{5,2,35}$

In the current study, we showed that Pae-induced apoptosis is closely related to the induction of ROS and the suppression of Akt activation in human lung cancer cells. Furthermore, drug-loaded nanoparticles exhibit clear 

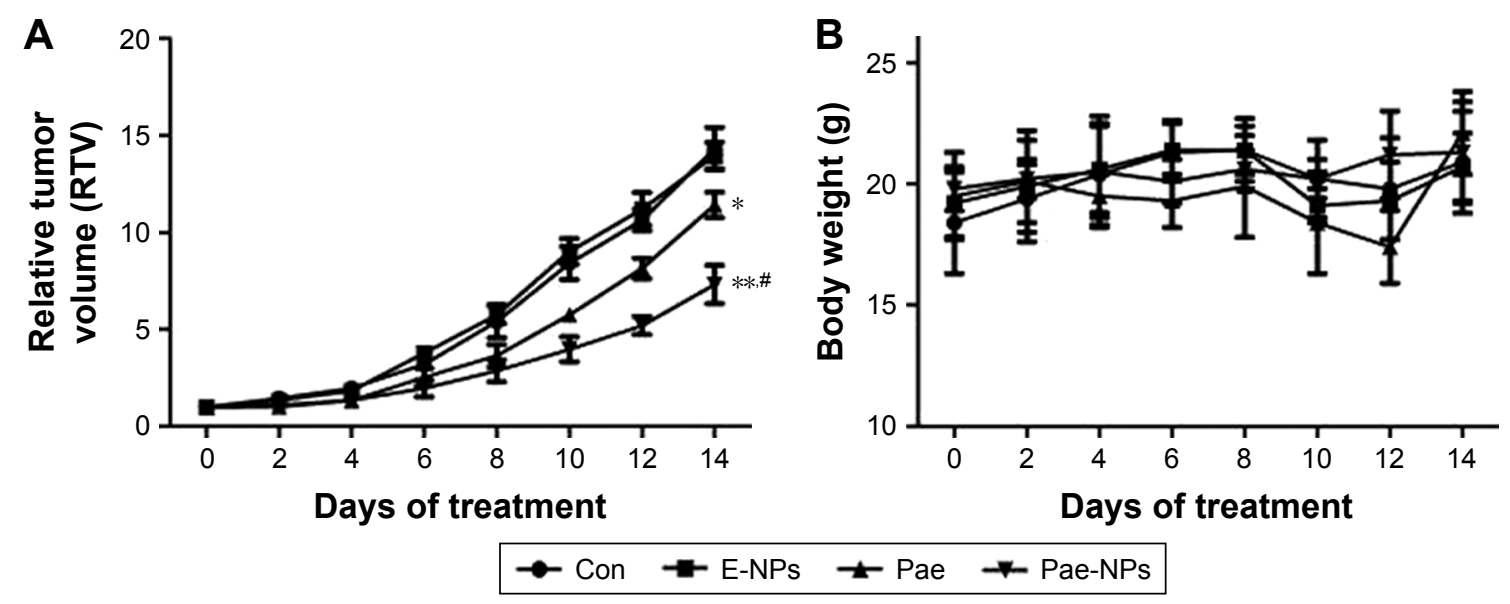

Figure 9 In vivo antitumor efficacy of Pae-NPs.

Notes: The mice were intravenously administered with PBS, E-NPs, free Pae, or Pae-NPs every 2 days for three consecutive injections. (A) Growth inhibition study in the A549 xenograft model. (B) Body weight changes for the tumor bearing mice after various formulations were given to mice on the indicated days. Data are represented as mean $\pm S D(n=6) . * p<0.05$, ** $p<0.01$, compared to the control group; ${ }^{*} p<0.05$, compared to the Pae group.

Abbreviations: Pae, paeonol; Pae-NPs, Pae-loaded nanoparticles; E-NPs, empty nanoparticles; SD, standard deviation; PBS, phosphate-buffered saline; Con, control.

advantages over free drug in inhibiting cell growth by the enhancement of cellular uptake and the subsequent generation of ROS, thereby strongly inducing cell apoptosis through regulation of the Akt pathway. Recent studies have shown that Pae has a synergistic effect with cisplatin in esophageal and hepatoma cancer cell lines, which indicates the potential of Pae as a chemosensitizer in conventional chemotherapy. ${ }^{36,37}$ A similar study is ongoing in the authors' laboratory, focusing on the synergistic effect and the underlying mechanisms of Pae and paclitaxel in several cancer cell lines.

\section{In vivo evaluation of the antitumor effect of Pae-NPs}

The aforementioned promising antitumor effects of Pae-NPs encouraged us to study the in vivo antitumor effects of PaeNPs in mice bearing A549 cell xenografts. Both free Pae and Pae-NPs showed superior antitumor effects compared with control and E-NPs. Furthermore, Pae-NPs exhibited the strongest antitumor efficacy (Figure 9A). As shown in Figure 9B, the mice in the control group and the treatment group showed no statistically significant differences in body weight throughout the evaluation. A literature search found no previous study of the antitumor effect of Pae-NPs, which makes the current study the first report of a nano-delivery system for Pae in cancer therapy. Moreover, the Kaplan-Meier analysis in Figure S2 demonstrates the superior therapeutic effect of Pae-NPs with the best survival among all the groups, which is in accordance with the tumor growth results in Figure 9.

Used in traditional Chinese medicine, Pae has a variety of pharmacological effects with lower toxicity compared with commonly used chemotherapeutics. It has previously been reported that Pae is a good chemo/radiosensitizer, which points to a novel strategy to improve the efficacy of chemotherapy or radiotherapy. ${ }^{9,36-38} \mathrm{Pae}$, in combination with cisplatin, had a significantly synergistic growth inhibitory effect on esophageal cancer cell lines. ${ }^{37}$ Meanwhile, Pae has protective effects on cisplatin-induced acute renal failure in mice. ${ }^{39}$ In addition, Pae also showed the potential property of the reversal of paclitaxel resistance, facilitating the sensitivity of breast cancer chemotherapy. ${ }^{38}$ Moreover, delivery of Pae using nanoparticles will enhance its antitumor effects and improve its pharmacokinetic and pharmacodynamic profile.

\section{Conclusion}

In this study, we prepared Pae-loaded mPEG-PCL nanoparticles with satisfactory DLC and EE. In vitro cytotoxicity studies indicated that, at lower doses, Pae-NPs achieved more cell apoptosis than the equivalent dose of Pae, as well as greater induction of intracellular ROS and consequent downregulation of p-Akt. The superior effect of Pae-NPs compared with free Pae was partly reversed by the antioxidant NAC. In vivo evaluation demonstrated a superior antitumor effect of Pae-NPs in a xenograft cancer model.

\section{Acknowledgment}

The study was partly supported by the National Natural Science Foundation of China (grant no 81572937; 81603647).

\section{Author contributions}

$\mathrm{CC}$ and $\mathrm{FJ}$ were involved in the fabrication and characterization of the nanoparticles. CC, HZ, and FJ were involved in the in vitro and in vivo evaluations. SR, HZ, and LQ were 
involved in the design and supervision of the whole study. $\mathrm{HZ}$ was involved in the analysis of protein expression. All authors contributed toward data analysis, drafting and revising the paper, read and approved the final manuscript, and agree to be accountable for all aspects of the work.

\section{Disclosure}

The authors report no conflicts of interest in this work.

\section{References}

1. Torre LA, Bray F, Siegel RL, Ferlay J, Lortet-Tieulent J, Jemal A. Global cancer statistics, 2012. CA Cancer J Clin. 2015;65(2):87-108.

2. Galluzzi L, Vitale I, Michels J, et al. Systems biology of cisplatin resistance: past, present and future. Cell Death Dis. 2014;5:e1257.

3. Li X, Li R, Qian X, et al. Superior antitumor efficiency of cisplatinloaded nanoparticles by intratumoral delivery with decreased tumor metabolism rate. Eur J Pharm Biopharm. 2008;70(3):726-734.

4. Hu Y, Xie J, Tong YW, Wang CH. Effect of PEG conformation and particle size on the cellular uptake efficiency of nanoparticles with the HepG2 cells. J Control Release. 2007;118(1):7-17.

5. Sun GP, Wan X, Xu SP, Wang H, Liu SH, Wang ZG. Antiproliferation and apoptosis induction of paeonol in human esophageal cancer cell lines. Dis Esophagus. 2008;21(8):723-729.

6. Yin J, Wu N, Zeng F, Cheng C, Kang K, Yang H. Paeonol induces apoptosis in human ovarian cancer cells. Acta Histochem. 2013;115(8): 835-839.

7. Chen B, Ning M, Yang G. Effect of paeonol on antioxidant and immune regulatory activity in hepatocellular carcinoma rats. Molecules. 2012; 17(4):4672-4683.

8. LiN, Fan LL, Sun GP, et al. Paeonol inhibits tumor growth in gastric cancer in vitro and in vivo. World J Gastroenterol. 2010;16(35):4483-4490.

9. Lei Y, Li HX, Jin WS, et al. The radiosensitizing effect of paeonol on lung adenocarcinoma by augmentation of radiation-induced apoptosis and inhibition of the PI3K/Akt pathway. Int J Radiat Biol. 2013;89(12): 1079-1086.

10. Kim SA, Lee HJ, Ahn KS, et al. Paeonol exerts anti-angiogenic and anti-metastatic activities through downmodulation of Akt activation and inactivation of matrix metalloproteinases. Biol Pharm Bull. 2009; 32(7):1142-1147.

11. Chunhu Z, Suiyu H, Meiqun C, Guilin X, Yunhui L. Antiproliferative and apoptotic effects of paeonol on human hepatocellular carcinoma cells. Anticancer Drugs. 2008;19(4):401-409.

12. Sun GP, Wang H, Xu SP, et al. Anti-tumor effects of paeonol in a HepAhepatoma bearing mouse model via induction of tumor cell apoptosis and stimulation of IL-2 and TNF-alpha production. Eur J Pharmacol. 2008;584(2-3):246-252.

13. Tan S, Ye J, Qian C, Ji C, Liu C, Wang J. Paeonol inhibits the proliferation of human colorectal carcinoma cells and synergic with chemotherapeutic agents. Saudi Med J. 2007;28(4):642-643.

14. Tsao JY, Tsai HH, Wu CP, et al. Release of paeonol-beta-CD complex from thermo-sensitive poly( $\mathrm{N}$-isopropylacrylamide) hydrogels. Int $J$ Pharm. 2010;402(1-2):123-128.

15. Wu RG, Dai JD, Wu FG, Zhang XH, Li WH, Wang YR. Competitive molecular interaction among paeonol-loaded liposomes: differential scanning calorimetry and synchrotron X-ray diffraction studies. Int $J$ Pharm. 2012;438(1-2):91-97.

16. Li X, Zhen D, Lu X, et al. Enhanced cytotoxicity and activation of ROSdependent c-Jun NH2-terminal kinase and caspase-3 by low doses of tetrandrine-loaded nanoparticles in Lovo cells - a possible Trojan strategy against cancer. Eur J Pharm Biopharm. 2010;75(3):334-340.

17. Liu J, Xu H, Zhang Y, et al. Novel tumor-targeting, self-assembling peptide nanofiber as a carrier for effective curcumin delivery. Int $J$ Nanomedicine. 2014;9:197-207.
18. Zhao J, Yan W. Simultaneous determinations of paeonol and palmatine hydrochloride in Shangshi aerosols by HPLC method. J Pharm Biomed Anal. 2005;38(3):571-575.

19. Chen Y, Shi L, Zhang L, et al. The molecular mechanism governing the oncogenic potential of SOX2 in breast cancer. J Biol Chem. 2008; 283(26):17969-17978.

20. Zhang L, Yang M, Wang Q, et al. 10-Hydroxycamptothecin loaded nanoparticles: preparation and antitumor activity in mice. J Control Release. 2007;119(2):153-162.

21. Zhang L, Hu Y, Jiang X, Yang C, Lu W, Yang YH. Camptothecin derivativeloaded poly(caprolactone-co-lactide)-b-PEG-b-poly(caprolactoneco-lactide) nanoparticles and their biodistribution in mice. J Control Release. 2004;96(1):135-148.

22. Li Y, Dong L, Jia A, Chang X, Xue H. Preparation and characterization of solid lipid nanoparticles loaded traditional Chinese medicine. Int $J$ Biol Macromol. 2006;38(3-5):296-299.

23. Wang M, Chen W, Zhang H, et al. Synthesis and characterization of PLLA-PLCA-PEG multiblock copolymers and their applications in modifying PLLA porous scaffolds. Eur Polym J. 2007;43(11):4683-4694.

24. van Vlerken LE, Duan Z, Seiden MV, Amiji MM. Modulation of intracellular ceramide using polymeric nanoparticles to overcome multidrug resistance in cancer. Cancer Res. 2007;67(10):4843-4850.

25. Davda J, Labhasetwar V. Characterization of nanoparticle uptake by endothelial cells. Int J Pharm. 2002;233(1-2):51-59.

26. Ivanova $D$, Bakalova $R$, Lazarova $D$, Gadjeva $V$, Zhelev Z. The impact of reactive oxygen species on anticancer therapeutic strategies. $A d v$ Clin Exp Med. 2013;22(6):899-908.

27. Zhou Y, Shu F, Liang X, et al. Ampelopsin induces cell growth inhibition and apoptosis in breast cancer cells through ROS generation and endoplasmic reticulum stress pathway. PloS One. 2014;9(2): e89021.

28. Park KW, Kundu J, Chae IG, et al. Carnosol induces apoptosis through generation of ROS and inactivation of STAT3 signaling in human colon cancer HCT116 cells. Int J Oncol. 2014;44(4):1309-1315.

29. Kim TH, Woo JS, Kim YK, Kim KH. Silibinin induces cell death through ROS-dependent down-regulation of Notch-1/ERK/Akt signaling in human breast cancer cells. J Pharmacol Exp Ther. 2014;349(2): 268-278.

30. Liu C, Gong K, Mao X, Li W. Tetrandrine induces apoptosis by activating reactive oxygen species and repressing Akt activity in human hepatocellular carcinoma. Int J Cancer. 2011;129(6): $1519-1531$.

31. Cassinelli G, Zuco V, Gatti L, et al. Targeting the Akt kinase to modulate survival, invasiveness and drug resistance of cancer cells. Curr Med Chem. 2013;20(15):1923-1945.

32. Martelli AM, Tabellini G, Bressanin D, et al. The emerging multiple roles of nuclear Akt. Biochim Biophys Acta. 2012;1823(12):2168-2178.

33. Meier P, Vousden KH. Lucifer's labyrinth - ten years of path finding in cell death. Mol Cell. 2007;28(5):746-754.

34. Chiantore MV, Vannucchi S, Mangino G, et al. Senescence and cell death pathways and their role in cancer therapeutic outcome. Curr Med Chem. 2009;16(3):287-300.

35. Ou Y, Li Q, Wang J, Li K, Zhou S. Antitumor and apoptosis induction effects of paeonol on mice bearing EMT6 breast carcinoma. Biomol Ther (Seoul). 2014;22(4):341-346.

36. Xu SP, Sun GP, Shen YX, Peng WR, Wang H, Wei W. Synergistic effect of combining paeonol and cisplatin on apoptotic induction of human hepatoma cell lines. Acta Pharmacol Sin. 2007;28(6):869-878.

37. Wan XA, Sun GP, Wang H, Xu SP, Wang ZG, Liu SH. Synergistic effect of paeonol and cisplatin on oesophageal cancer cell lines. Dig Liver Dis. 2008;40(7):531-539.

38. Cai J, Chen S, Zhang W, et al. Paeonol reverses paclitaxel resistance in human breast cancer cells by regulating the expression of transgelin 2 . Phytomedicine. 2014;21(7):984-991.

39. Lee H, Lee G, Kim H, Bae H. Paeonol, a major compound of moutan cortex, attenuates cisplatin-induced nephrotoxicity in mice. Evid Based Complement Alternat Med. 2013;2013:310989. 


\section{Supplementary materials}

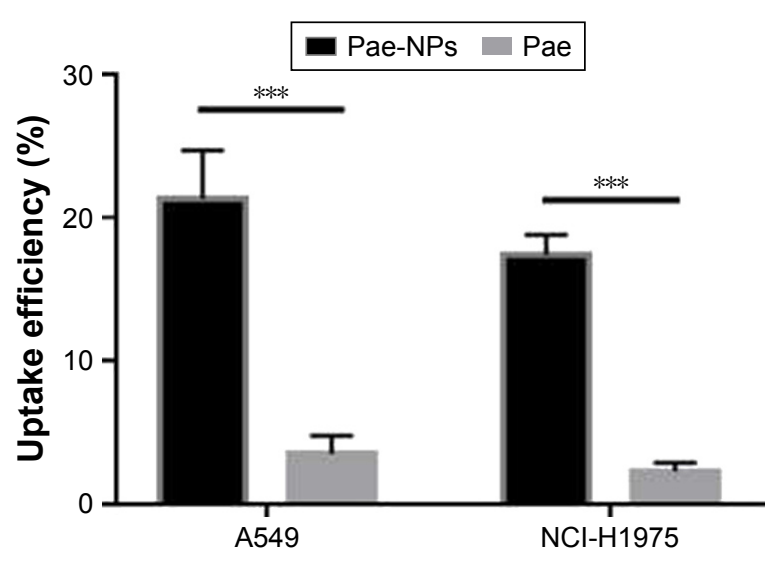

Figure SI Uptake efficiency of Pae-NPs and free Pae by two kinds of lung cancer cells $(n=3 ; * * * p<0.001)$.

Abbreviations: Pae, paeonol; Pae-NPs, Pae-loaded nanoparticles.

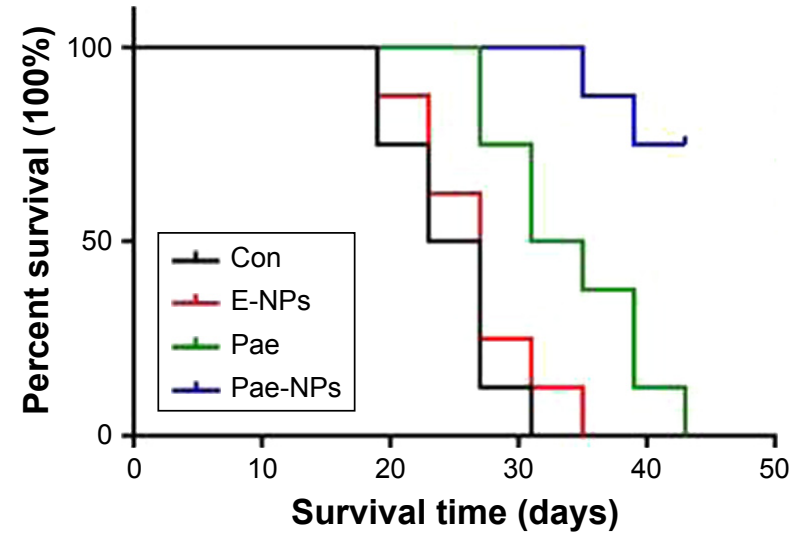

Figure S2 Kaplan-Meier curves showing the survival of xenograft mice treated with different protocols. (Log-rank test; $p<0.000$ I).

Abbreviations: Pae, paeonol; Pae-NPs, Pae-loaded nanoparticles; E-NPs, empty nanoparticles; Con, control.
International Journal of Nanomedicine

\section{Publish your work in this journal}

The International Journal of Nanomedicine is an international, peerreviewed journal focusing on the application of nanotechnology in diagnostics, therapeutics, and drug delivery systems throughout the biomedical field. This journal is indexed on PubMed Central, MedLine, CAS, SciSearch $\AA$, Current Contents $\AA /$ Clinical Medicine,

\section{Dovepress}

Journal Citation Reports/Science Edition, EMBase, Scopus and the Elsevier Bibliographic databases. The manuscript management system is completely online and includes a very quick and fair peer-review system, which is all easy to use. Visit http://www.dovepress.com/ testimonials.php to read real quotes from published authors. 